\title{
Poesía religiosa del padre Teófilo Gaivao Mier como vehículo de la comunicación social
}

\author{
Father Teofilo Gaivao Mier religious poetry \\ as a medium to social communication
}

\author{
Olga Beatriz Naranjo Riofrío ${ }^{1}$ \\ olgab_naranjo@hotmail.com
}

\begin{abstract}
Resumen
El objetivo principal de este estudio es difundir la poesía religiosa que escribe el padre Teófilo Gaivao Mier durante las diferentes etapas de su vida mediante los poemas Mensaje de Paz, Navidad Infantil, Décimas Sacras y Gozos a la Virgen de Montserrat. Esta obra literaria quiere expresar los sucesos históricos, teológicos y motivacionales que inspiró al sacerdote a escribir cada una de sus poesías. En base al diseño metodológico, este artículo responde a la línea de investigación de la carrera de Comunicación Social con mención en Producción Audiovisual y Multimedial de la Universidad Politécnica Salesiana: Comunicación, cultura e interculturalidad, estudios teóricos y experiencias prácticas. El estudio sobre la Poesía Religiosa del padre Teófilo Gaivao Mier como vehículo de la comunicación social está emprendido desde el paradigma cualitativo y cuantitativo. La muestra seleccionada son 68 laicos comprometidos y miembros de la vida consagrada de la Iglesia Católica. Se utiliza la encuesta como método cuantitativo para determinar la falta de familiaridad sobre la poesía religiosa. El alcance de este estudio investigativo es exploratorio. A modo de conclusión se propone a los encuestados leer poesía religiosa y el $90 \%$ respondió afirmativamente que le interesaba. Por lo tanto la causa del por qué no se la lee es porque no se la difunde como se debe. En la actualidad existen personas ansiosas por conocerla y descubrir la poesía con musicalización vallenata del padre Teófilo Gaivao.
\end{abstract}

\section{Palabras clave}

Poesía, religión, comunicación, sacerdote, Colombia.

Forma sugerida de citar:

Naranjo Riofrío, Olga Beatriz (2016). Poesía religiosa del padre Teófilo Gaivao Mier como vehículo de la comunicación social. Universitas, XIV(25), pp. 61-88.

1 Universidad Politécnica Salesiana. 


\begin{abstract}
The main objective of this study is to spread the religious poetry that write Father Theophilus Gaivao Mier during the different stages of his life through poems Message of Peace, Children's Christmas, Sacred tenths and Joys to the Virgin of Montserrat. This literary work intends to express the historical, theological and motivational events that inspire to the priest for write in each one of his poetics. Based on the methodological design, this article responds to the research line of the career of Social Communication with mention in Production Audiovisual and Multimedia of the Salesian Polytechnic University: Communication, Culture and multiculturalism, theoretical studies and practical experiences. The study on the Religious Poetry of Father Theophilus Gaivao Mier Theophilus as a vehicle of social communication is undertaken from the qualitative paradigm and quantitative paradigm. The sample selected is 68 lay people and people of the consecrated life of the Catholic Church. The survey was used a quantitative method to determine the unfamiliarity in religious poetry. The scope of this research study is exploratory. It propose to the respondents to read religious poetry and $90 \%$ responded affirmatively. Therefore the cause of why is not being read it is because it is not broadcast. Nowadays there are people eager to know and discover the poetry with vallenato music composition of Father Theophilus Gaivao Mier as a vehicle for social communication.
\end{abstract}

\title{
Keywords
}

Poetry, religion, communication, priest, Colombia.

\section{Introducción}

El período de las dos últimas décadas del siglo XIX y las primeras del siglo XX impactó en las manifestaciones literarias religiosas que, por las características históricas de la época, debieron expresarse con mucha cautela. Estos comportamientos que venían retocados por el intelecto europeo, romántico, estético, se marcaron en América y particularmente, en lo que toca señalar, Ecuador y Guayaquil. En Ecuador, a pesar de ser un país católico la poesía religiosa aún está escondida en nuestra época. La poca o casi nula información que se tiene sobre poesía religiosa todavía es incierta. Se da más importancia al mundo, a los placeres de cada día, y no a Dios ni a la religión.

En este artículo no se puede hablar simplemente de poesía religiosa sin enlazarla con la comunicación social porque la poesía además de transmitir 
una información que narra hechos y emociones también está vinculada con el sistema más abundante que existe desde la prehistoria: la comunicación. El título de Poesía religiosa como vehículo de comunicación social comprende que cuando un poeta decide escribir poesía; él lo redacta, lo publica y "alguien", eventualmente, lo lee. Este proceso, que va de escritor a lector, tiene todas las características que definen un proceso comunicacional. Francisco Chico citado por López afirma que todo texto, literario, tiene una función comunicativa y social:

El acto de comunicación es el acto por el cual un individuo, conociendo un hecho perceptible asociado a un cierto estado de conciencia, realiza este hecho para que otro individuo comprenda el fin de ese comportamiento y reconstituya en su propia conciencia del primero (Lopéz, 2014, p. 555).

Es decir, que interviene los elementos esenciales que lo componen: el poeta es el emisor y, a su vez elabora un poema convirtiéndose en el mensaje, y finalmente éste va dirigido a un receptor. Esta consciencia particular se manifiesta por medio de las palabras: signos sociales básicos. El fenómeno filosófico poético está determinado por las maneras de comunicación social que el poeta instituye, y el signo ideológico por excelencia, conformado a través de esa comunicación social organizada es la palabra. La palabra es adaptada por el poeta, agrupado al lenguaje interno, y restituida con los significados concedidos, significación establecida por su biografía, en nexo permanente con lo histórico biográfico. La palabra, como lenguaje interno, participa en la cognición misma del poeta.

Además la realidad filosófica del poeta está determinada por el conjunto de las relaciones sociales en las cuales el poeta se sitúa. Esto demanda del lugar donde él surge y la capacidad de mociones para su escritura. En este caso Taylor señala: "Es un hecho común a todos los seres humanos que la comunicación y la experiencia sobre poesía religiosa accesible para cada sujeto depende de la sociedad donde han nacido" (2006, p. 70). El presbítero Teófilo Gaivao Mier es colombiano, hace 13 años se encuentra radicado en Ecuador y es párroco de la Iglesia Nuestra Señora de Montserrat. Su nacionalidad y sus costumbres lo hacen ser un cantautor único, puesto que se inspiró y compuso unos gozos a la Virgen aquellos días cercanos a su fiesta patronal. El sacerdote decidió investigar la historia desde su llegada a la Ciudadela 9 de Octubre en la ciudad de Guayaquil. 
Sus poemarios buscan expresar las emociones o impresiones del mundo en las etapas sociopolíticas económicas que vivió, como por ejemplo: La reforma agraria de Colombia, durante el siglo XX en el periodo del presidente Carlos Lleras Restrepo. En sus líneas poéticas es común el uso de la rima consonante en distintos versos octosílabos, endecasílabos, decasílabos y otros tipos de versos. Así como también se busca un breve análisis de los poemas sobre el contexto histórico, teológico y motivacional que llevó a escribir cada una de sus obras. Obras inéditas y además gozan de musicalización vallenata. Detalles que sugieren los estudiantes según el análisis elaborado por el docente Magister Hugo Merchán en su trabajo de investigación: "Estudio exploratorio sobre las inferencias en los textos de poesía religiosa, en los jóvenes universitarios de la Carrera de Comunicación Social de la Universidad Politécnica Salesiana de Guayaquil en el año 2015”, destaca que la importancia de presentar una poesía distinta:

Las estrategias propuestas para rescatar la poesía religiosa en la ciudad de Guayaquil por los participantes entrevistados, en un 38,39\% recomiendan difundir por medios interactivos dichos poemas; un 18,75\% sugiere realizar actividades de docencia o culturales, y el resto, con un 13,5\%, en que se debe de musicalizar y volver más atractiva a la poesía religiosa (Merchán, 2015, p. 179).

Por lo tanto he aquí la gran importancia de compartir la poesía religiosa del padre Teófilo Gaivao Mier como vehículo de la comunicación social puesto que su poesía es llamativa y con música vallenata autóctona de la Costa Caribe colombiana, su lugar de nacimiento. Una poesía inspirada en la Mariología y la Cristología.

\section{Revisión del estado del arte y fundamentación. Marco teórico}

\section{Teoría marxista}

Con la crítica literaria marxista se busca ubicar la literatura en los ámbitos sociales, económicos e históricos, es decir, comprender cómo las ideas se desplegaron en la obra literaria en el contexto de los valores que transitaban en la sociedad dentro de su período. La teoría crítica pretende vincular 
la literatura a la lucha de clases, a los problemas entre grupos sociales que combaten por el poder político y económico. Además esta teoría crítica marxista consiste en hallar cómo la ideología actúa en el lenguaje para enmascarar ataques sociales entre los diferentes grupos económicos.

\section{Teoría estilística}

La estilística es una forma de estudio de la obra literaria que se basa en el estilo de la misma y en el modo en el que el lenguaje está utilizado en dicha obra. Y es, precisamente, debido a este último aspecto por lo que el vocabulario, que aparece en el siglo XIX, está íntimamente relacionado con la lingüística. La estilística trata al signo poético en un doble sentido: atendiendo a su significante y a su significado, pudiéndose entender desde una dimensión psicologista, donde la intuición desempeña un rol activo de gran importancia que viene a significar la base de los estudios estilísiticos.

\section{Teoría hermenéutica}

La hermenéutica es la teoría de interpretar textos, especialmente sobre las escrituras sagradas y los textos filosóficos y artísticos. La hermenéutica representa una teoría de la verdad y el método que expresa la universalización del fenómeno interpretativo desde la historicidad concreta y personal. Para Mario Bunge es la interpretación de textos en la teología, la filología y la crítica literaria; $y$, en la filosofía, es la doctrina idealista según la cual los hechos sociales son símbolos o textos que deben interpretarse en lugar de describirse y explicarse objetivamente.

\section{Delimitación del problema}

¿Cuáles son las razones del por qué en Guayaquil no se lee la poesía religiosa?

\section{Pregunta de Investigación}

¿Influirán las variables de insuficiencia de información y poca difusión sobre el por qué no se lee la poesía religiosa? 
¿Cuál será el significado de la poesía religiosa para los laicos y personas de vida consagrada?

Hipótesis: La poca o casi nula difusión de la poesía religiosa ocasiona que las personas la desconozcan.

Variable independiente: Poca difusión

Variable dependiente: Insuficiencia de información

\section{Objetivo General}

Difundir mediante este artículo la poesía religiosa del padre Teófilo Gaivao Mier como vehículo de la comunicación social.

\section{Justificación}

La poca o casi nula información de la poesía religiosa y además el consumismo en que se vive día a día conlleva a que la poesía religiosa difícilmente sea leída. La causa del por qué no se la lee es porque no la difunden como se debe, además se presta mayor importancia al mundo, a los placeres de cada día, y no a Dios ni a la religión.

\section{Materiales y métodos}

\section{Metodología}

Todo investigador dispone de una serie de herramientas y métodos para alcanzar los resultados de la investigación científica de manera eficiente y eficaz. Por lo tanto, la metodología empleada en la presente investigación sirve para acercarse a la problemática sobre poesía religiosa. En base al diseño metodológico, este artículo responde a la siguiente línea de investigación de la Carrera de Comunicación Social con mención en Producción Audiovisual y Multimedial: Comunicación, cultura e interculturalidad, estudios teóricos y experiencias prácticas. El estudio sobre la Poesía Religiosa del padre Teófilo Gaivao Mier como vehículo de la comunicación social estuvo emprendido desde el paradigma cualitativo y paradigma cuantitativo, como método cuantitativo se utilizó la encuesta realizada en el mes de agosto ana- 
lizando en primera instancia la falta de familiaridad sobre poesía religiosa. El alcance de este estudio investigativo es meramente exploratorio.

\section{Muestra}

La muestra de estudio fueron laicos comprometidos y miembros de vida consagrada de la Iglesia Católica aquellos que de alguna manera están relacionados con la religión, la fe y al contacto permanente con Dios. Se escogió a 500 personas como población y se calculó como muestra a 68 personas.

\section{Método para determinar el tamaño de la muestra (n)}

\section{Parámetros}

$\mathrm{N}=500$

Nivel de confianza $=90 \%$

$\mathrm{Z} \pm 1,65$

Error muestral $=10 \%$

$\mathrm{P}=0,50$

$\mathrm{Q}=0,50$

$\mathrm{n}=$ ?

$\mathrm{N}=$ tamaño de la población.

$\mathrm{Z}=$ valor obtenido mediante los niveles de confianza. Los valores de $\mathrm{Z}$ más utilizados y sus niveles de confianza son:

\begin{tabular}{|l|l|l|l|l|l|l|l|}
\hline Valor de $\mathbf{Z} \pm$ & $\mathbf{1 , 1 5}$ & $\mathbf{1 , 2 8}$ & $\mathbf{1 , 4 4}$ & $\mathbf{1 , 6 5}$ & $\mathbf{1 , 9 6}$ & $\mathbf{2 , 2 4}$ & $\mathbf{2 , 5 8}$ \\
\hline Nivel de confianza & $75 \%$ & $80 \%$ & $85 \%$ & $90 \%$ & $95 \%$ & $97,5 \%$ & $99 \%$ \\
\hline
\end{tabular}

$\mathbf{P}=$ proporción de individuos que posee la población. Suele utilizarse un valor constante de 0,50 .

$\mathbf{Q}=$ proporción de individuos que no posee esa característica, equivale a 1-p. $\mathbf{e}=$ límite aceptable de error muestral que cuando se desconoce su valor, se coloca entre un porcentaje el $1 \%$ y $10 \%$.

$\mathbf{n}=$ el tamaño de la muestra que se desea descubrir. 
Fórmula empleada

$$
\begin{aligned}
& n=\frac{Z^{2} \times P \times Q}{e^{2}} \\
& n=\frac{(1,65)^{2} \times 0,50 \times 0,50}{0,10^{2}} \\
& n=\frac{2,7225 \times 0,25}{0,01} \\
& n=\frac{0,680625}{0,01} \\
& n=68,0625
\end{aligned}
$$

\section{Desarrollo}

\section{Mensaje de paz}

La poesía de Mensaje de paz gira en torno a la coyuntura de la época. La Iglesia Universal afrontaba la crisis posconciliar provocada por los cambios introducidos por el Concilio Vaticano II. Pieris lo describe: "aquella comunidad de creyentes, uniforme en raza, lengua y cultura, se volvió, para los paganos, creíble y a su vez evolucionó hasta convertirse en una Iglesia verdaderamente católica, enraizada en multitud de culturas" (2005, p. 36). A su vez, el mundo experimentaba los cambios sociopolíticos con la afirmación y expansión del sistema de gobierno comunista afianzado por la doctrina Marxista-Leninista-Maoísta. En palabras textuales de Klaus Meschkat, así lo describe:

Esta evocación de una revolución geográficamente distante no significa que los dirigentes del movimiento revolucionario hayan orientado sus actos en 
los escritos de Marx, Lenin o Trotski, que en su mayoría no habían siquiera leído. Sin estas instrucciones de afuera, supieron dónde se podía atacar el sistema de un capitalismo dependiente dominante en sus países (Meschkat, 2010, p. 3).

Por todo el universo se proponía como modelos los procesos revolucionarios que supuestamente habían liberado del capitalismo salvaje a países como: Rusia, China, Cuba y Albania. Colombia integró la lista de los países que desde sus orígenes resistieron las estructuras injustas de los sistemas de gobiernos impuestos por una clase oligárquica y dominante. Tocado por el germen de la revolución en las primeras contiendas de las luchas campesinas, -estirpe a la que pertenecen sus padres-, se interesara en apoyar el nuevo paradigma que se presentaba como la única propuesta para construir una sociedad igualitaria, y, por consiguiente, un mundo más justo y sin opresión.

En ese momento se intentaba desarrollar la reforma agraria fallida propuesta por el presidente Alberto Lleras Restrepo en su período de gobierno. Esta coyuntura fue aprovechada por el campesinado colombiano para reivindicar las tierras que en décadas anteriores les arrebataron los grandes terratenientes, quienes, a su vez, aprovechándose de la lucha partidista que libraban liberales y conservadores, los habían despojado de los únicos medios de subsistencia que tenían. En palabras de Skidelsky:

La influencia de Carlos Lleras Restrepo en la organización y planificación rigurosa a largo y mediano plazo del Estado, tuvo un gran ascendiente en el siglo XX, un siglo que se caracterizó por la vigencia de un ciclo liberal, intervencionista, entre los años treinta y setenta -durante la fase vital de Lleras-, y que fue seguido de conservador, de repliegue gubernamental y desregulación económica (Skidelsky, 1995, pp. 1-26).

Los campesinos aprovecharon las circunstancias para establecer la más grande y sólida organización nacional haciendo eco de lemas como: "la unión hace la fuerza" y "la tierra es de quien la trabaja"; emprendieron la más grande y agresiva campaña de recuperación de tierras que el país conoció en toda su historia. Mientras esto sucedía el escritor se inspira y vincula la comunicación social con en el Antiguo Testamento cuando Dios al elegir Israel simplemente lo elige y proclama: "Porque tú eres pueblo santo para el Señor tu Dios; el Señor tu Dios te ha escogido para ser pueblo suyo de entre todos los pueblos que están sobre la faz de la tierra" (Dt 7:6). El 
Mensaje de paz es un poema rima consonante de diez versos en cada estrofa, con melodía de ritmo paseo vallenato, un carácter marcadamente teológico y cristológico.

Mensaje de paz obra con melodía de ritmo paseo vallenato publicado en Antología. La poesía religiosa en Guayaquil (Rubio, 2015).

Representando las sabanas, mi región, cuna de artistas y grandes compositores Vengo a la cita que nos hace este folklor, donde se escoge entre juglares los mejores;

Desde la Villa del Cacique Tacasuan, tierra muy próspera de paz y de reposo Traigo un mensaje para el gran cacique upar, mil bendiciones del Cristo Milagroso.

Porque al valle de su honra, otrora valle de paz la violencia con su sombra, hoy azotándolo está

Dios mío que pase esta hora, cese la violencia ya.

(Mensaje de paz, 1996)

Alrededor del diálogo con Dios, Gaivao le implora al "Cristo Milagroso", "Cristo Moreno" o "El Señor de los Milagros" para que Él interceda por la paz de su pueblo, la Villa del Cacique Tacasuan, ubicada a $50 \mathrm{~km}$ de Sincelejo, Departamento de Sucre en Colombia. La Villa del Cacique Tacasuan hoy llamada San Benito Abad considerada tierra de mitos, leyendas y milagros, enclavada en las riberas del legendario Río San Jorge; lugar donde habitaban la familia Gaivao Mier: Don Teófilo Gregorio su padre, tenía 21 años, y su madre Ana de los Ángeles, 17. La pareja joven que a temprana edad sabía que se amaban lo suficiente para conformar un hogar. Aquel camino que ninguno de los dos soñó, carecía de suficientes recursos económicos para brindarle la mejor calidad de vida a la familia que crecía rápido. Debido a los problemas sociopolíticos de la época prácticamente los estudios elementales que lograron los suspendieron por la necesidad de trabajar.

Su principal patrimonio era la fe ciega en el Cristo Milagroso de la Villa, la misma que habían heredado de sus antepasados y de los devotos procedentes de la geografía nacional e internacional, quienes han hecho una costumbre sagrada peregrinar al menos dos veces al año a la Basílica Menor del Señor de los Milagros, donde aún llegan en romerías, otras en familia, a presentar sus ofrendas en gratitud por los favores recibidos. Y es aquí que Dios recompensa a quienes creen sin haber visto. El evangelista Mateo en el ca- 
pítulo 7:8 nos afirma que la oración recibirá respuesta: "Pedid, y se os dará; buscad, y hallaréis; llamad, y se os abrirá. Porque todo el que pide, recibe; y el que busca, halla; y al que llama, se le abrirá. ¿O qué hombre hay entre vosotros que si su hijo le pide pan, le dará una piedra...?" (Mt 7:8).

Si algún día puedo, como lo hizo Jesucristo, subir al cielo donde se encuentran los santos

Le pediré que nuevamente el paraíso, tenga su sede en este pueblo vallenato; $\mathrm{Y}$ si es posible que mande a Francisco el hombre, Fredy Molina Juancho Roy, Héctor Zuleta

Para que un pueblo de leyenda y tradiciones, por la violencia no se muera de tristeza.

Y si fuere necesario bendigo al Guatapurí, paque' su cauce sagrado la paz pueda revivir

Y como en tiempos pasados podamos vivir aquí

Porque es muy triste ver como todo ha cambiado, poquito a poco se fue perdiendo el encanto

Ya que las balas muchas vidas han segado, en esta tierra querida de Pedro Castro.

(Mensaje de paz, 1996)

\section{Navidad infantil}

Luego de tres intentos fallidos, un 15 de marzo de 1955 llegó a sus vidas, Teófilo, el varón que tanto habían deseado. Sucedió después de cinco años de vida matrimonial fruto del amor. Así lo confirma el P. Caffarel en las notas de Nouvelle Revue Théologique citado por Alain Mattheeuws:

El acto conyugal es la expresión y la actualización del acto interior de dos personas dándose la una a la otra. La esencia de este acto es ser, a la vez, 'don' recíproco y 'don' común. Darse el uno al otro para darse juntos, teniendo en cuenta que el 'don' recíproco no es un simple medio en relación a este 'don' común, sino que el 'don' recíproco y el 'don' común son un solo mismo acto. Porque ellos se aman, sin amor, este 'don' es ininteligible, los esposos se entregan el uno al otro no solamente en vista de una pertenencia mutua, sino, al mismo tiempo y de manera indisociable, en vista de un 'don' común al otro (Mattheeuws, 2015, p. 154). 
La nupcialidad que aparece entre ellos la consideran como forma de gratitud del Amor de Dios hecho carne en sus existencias. Según manifiestan sus padres, el acontecimiento lo interpretaron como una bendición especial de las tantas que el Señor les había regalado y por eso, no tardaron en presentarlo ante el Cristo Milagroso de la Villa. Convencidos de que, bajo su cuidado y protección, el pequeño crecería sano, salvo e inclinado hacia Dios. Así lo dice Juan Pablo II: "El hijo es fruto del amor y signo de esperanza, si es fruto de un don recíproco de amor llega a ser, para los padres, un don para ambos, un don que «brota del don»" (Juan Pablo II, 1989, p. 92). $\mathrm{Su}$ nombre previamente escogido ya indicaba lo que estaba llamado a ser. Teófilo es el destinatario del relato de Lucas. "Teófilo" significa "amado por Dios" o "amante de Dios". Es figura del discípulo que, al recibir el anuncio, sabe que es "amado por Dios" y desea con el corazón llegar a ser él también "amante de Dios" (Fausti, 2007, p. 18).

Teófilo sabe que es el "amado por Dios" y tiene una misión en la tierra que todavía desconoce. Su nacimiento es virtuoso y lleva en sus venas el don de la música y la composición. Él quiere retribuir tal amor con el que fue creado y compone Navidad Infantil de versos endecasílabos y tridecasílabos donde manifiesta en este apartado el Nacimiento de Jesús, aquel Niño que Dios Padre envió al mundo para que se salvase. El evangelio de Juan nos dice: "Porque de tal manera amó Dios al mundo, que dio a su Hijo unigénito, para que todo aquel que cree en Él, no se pierda, mas tenga vida eterna. Porque Dios no envió a su Hijo al mundo para juzgar al mundo, sino para que el mundo sea salvo por Él" (Juan 3,16-17). Navidad Infantil se encuentra publicado en la Antología. La poesía religiosa en Guayaquil (Rubio, 2015 p. 46).

Oye mamá en diciembre nace un niño,

Y mis abuelos me han dicho que viene a redimirnos,

Si eso es verdad dime pronto por favor,

Porque si ese es Jesucristo se lo cuento a mis amigos;

Si allá en la Iglesia los sacerdotes,

Me enseñan siempre aquel es un Dios

(Navidad Infantil, 1977)

Balthasar citado por Carlos Casale: "En Cristo se reconoce que el Dios creador es nuestro Padre efectivo, porque Jesús se ha manifestado como 
Hijo de modo único. Sin que lleguen a confundirse que Jesucristo aparece como el mediador absoluto de la salvación" (Casale, 2000, p. 398). En consecuencia Jesús vino a la tierra para demostrarnos que su amor es infinito. Amor que difiere del fraternal, del amor ágape, del amor eros y del amor al prójimo. Existe el amor entre Dios y Jesús: ambos la misma persona de la Santísima Trinidad. Stein lo aclara:

El amor desbordante con el que el Padre engendra al Hijo y le da su esencia, y con el Hijo recibe esta esencia y se la devuelve al Padre. De esta manera el alma vive de la gracia por el Espíritu Santo, ama en Él al Padre con el Amor del Hijo y al Hijo con el Amor del Padre (Stein, 2004, p. 349).

Por qué motivos tienen que mentirle al niño

Por qué razón no le dicen la verdad de Jesucristo,

Crucificado, pero se encuentra en el cielo,

recordando a todos los hombres que lo amaron en silencio,

y si tú quieres no te condenes,

busca en la tierra la salvación.

(Navidad Infantil, 1977)

P. Fernández citado por Sánchez Alberto lo recalca:

El amor es justamente la apertura a lo valioso de la realidad, de las cosas que nos rodean. El amor, es un explorador o un guía que busca los valores, que es capaz de ir ampliando cada vez más la esfera de valores accesibles al hombre. El que ama busca lo valioso en todos los órdenes: no sólo se complace en el valor sensible, sino que busca la belleza de la naturaleza, el resplandor de la verdad, el valor de la amistad (Sánchez, 2011, p. 96).

En la formación de Teófilo, sus progenitores, Don Gregorio y María de los Ángeles, tanto con sus palabras como con su testimonio de vida, le inculcaron desde pequeño los valores humanos y cristianos los cuales fueron la clave para obtener los triunfos cosechados en su vida personal. Para la Psicología Evolutiva -la primera y segunda infancia-, el ser humano absorbe de su entorno los elementos que van a constituir el desarrollo de su conducta posterior. En esta etapa en la que se compara con una hoja de papel en blanco donde el artista bien puede plasmar un ángel o un demonio. En el caso de los padres, pueden hacer de su hijo una persona con la que haga el bien o el 
mal, según lo que siembren en él y la manera afectiva y efectiva según como lo acompañen en su desarrollo evolutivo, así lo define:

A los seis años las líneas esenciales de la personalidad de un sujeto están ya determinadas; lo prueba el hecho de que los errores de educación o las frustraciones afectivas verificadas durante los primeros años de edad influyen negativamente en toda la vida siguiente. Por este motivo la atención de los educadores se ha ido trasladando en estos últimos tiempos a los primerísimos años de la vida. La cocción del barro de esta vasija frágil que es el hombre se realiza precisamente durante esos años; después podrá ser embellecida o afeada mediante líneas o dibujos más o menos acertados; podrá retocarse, pero no remodelarse. Las primeras impresiones son las que dejan la señal más profunda e indeleble (Casanova, 2007, p. 22).

\section{Décima Sacra}

Dentro de Teófilo se despertaba cada vez con mayor intensidad el deseo de asistir a la escuela, y desde entonces se esmeró para lograrlo. A pesar de la corta edad, ya sabía que su futuro no estaba en la pesca ni en el ejercicio de vendedor ambulante que desempeñó por varios años. Por eso, paralelas a estas actividades de trabajo, transitaba por su mente una gran aspiración que gracias al optimismo con el que vino al mundo, siempre la veía posible. Con la confianza que lo caracterizaba finalmente llegó a ser lo mismo, pero en dimensiones diferentes: pescador de hombres. Así lo relata en el libro del evangelista Lucas:

-Maestro, hemos estado trabajando toda la noche sin pescar nada; pero, puesto que tú lo mandas, echaré las redes-. Cuando lo hicieron, recogieron tal cantidad de peces que las redes se rompían. Al ver esto, Simón Pedro se puso de rodillas delante de Jesús y le dijo: -¡Apártate de mí, Señor, porque soy un pecador!-. Pero Jesús dijo a Simón: -No tengas miedo. Desde ahora vas a pescar hombres. Entonces llevaron las barcas a tierra, lo dejaron todo y se fueron con Jesús (Lucas 5:1-11).

Jesús aceptó un pecador y aun así lo preparó en su labor de "pescar hombres". Pedro sabía que como pecador no tenía la capacidad suficiente de estar en la presencia de Cristo. Jesús, en su infinitiva misericordia, no desprecia al pecador contrito sino que odia al pecado, y en consecuencia lo designa a servicio. Así pues Él edifica su iglesia y los hace Pescadores de hombres. 
De la misma manera ocurrió con Teófilo que desde un inicio sabía lo que estaba llamado a ser. Teófilo tuvo que leer textos de filosofía y librarse de las confrontaciones ideológicas con su hermana mayor para concluir con el distanciamiento que había mantenido aparentemente con Dios. Aunque le costó derramar numerosas lágrimas, al final produjo sus frutos. Y así, mientras crecía intelectualmente por su propia convicción, y aplicando el siguiente paradigma: "La duda metódica de Descartes consiste en eliminar la duda y encontrar algo seguro e indudable, por lo que la duda se plantea como un paso para la certeza; será un medio, no un fin en sí misma" (Morillo-Velarde, 2011, p. 54). Para dar ese paso fue determinante la formación sólida que desde su niñez había recibido de sus padres, de los sacerdotes misioneros de Burgos, España, de las hermanas Catequistas Misioneras que establecieron allí su convento y de los maestros de la escuela de Primaria, quienes eran verdaderos apóstoles de la educación.

Décima Sacra es una obra de seis estrofas cuya rima es de diez versos octosílabos inspirados en su vocación sacerdotal, que a su vez es considerada un misterio inexplicable que nadie que la posee puede explicar ni el cómo ni el cuándo la consigue, puesto que es un don que se da desde el Cielo. Bien la aceptan o rechazan porque no se puede imponer, sino que se ofrece con absoluta voluntad. Corresponde a quien es llamado por el discernimiento.

Grün, Anselm define al sacerdote como:

Dirigente religioso que visiblemente se distingue de los seguidores de una religión en virtud de una gracia especial y de su función mediadora entre el hombre y la divinidad. Esta definición subraya algo importante: el sacerdote, bien desde su nacimiento, bien en virtud de una consagración especial, posee una fuerza particular: tiene una calidad de poderes divinos. Un poder que se escapa a nuestro control (2002, p. 8).

Cuando pescando yo andaba,

En la ciénaga y el río,

Logré escuchar un zumbío,

De alguien que por ahí pasaba,

Y como no me paraba

Porque yo seguía pescando,

Ese alguien se fue acercando,

$\mathrm{Y}$ con cierto frenesí,

Me dijo vine por ti,

Ven que te andaba buscando.

(Décimas Sacras, 2016) 
En el caso del padre Teófilo Gaivao Mier, aun en este momento cuando ya cumplió los veintinueve años de vida sacerdotal, no se sabe explicar cómo se dio el proceso, ni cómo se facilitaron las condiciones para que Jesús depositara en él la gran responsabilidad de ser su discípulo y ministro del altar. La mayor parte, confiesa, la puso Dios y él no, "siempre he sido y seguiré siendo una persona con muchas debilidades y flaquezas, pero también con una fe y confianza inmensa".

\section{Virgen de Montserrat}

Desde los siete años asistía los sábados a las clases de música donde tenía afinidad con un compañero cantante y compositor. Ambos desde aquella edad escribían letrillas de su propia inspiración y fue así como el padre Teófilo descubrió su pasión por la música. El padre Teófilo considera que el artista compone y canta según el estilo de vida que lleva. Sin duda, por ser un servidor de Dios, sus canciones siempre van impregnadas de una alta dosis de espiritualidad, aunque éstas también son de estilo romántico. Debido a la vocación religiosa adquirida desde pequeño, y luego inclinarse por el sacerdocio, vive de su religión cristiana católica, por consiguiente, se regocija con Dios a quien considera vital fuente de inspiración. El padre Teófilo comenta que cuando la musa lo asalta, plasma en ella sus canciones, incluso cuando son aparentemente mundanas: "el mensaje de Dios, siempre está allí, no porque me lo proponga sino porque espontáneamente brota de mi interior".

Comenta que cuando participó en el Festival Internacional de Vallenato, sus colegas y superiores eclesiásticos, se sorprendieron de ver cómo un sacerdote se atrevía a cantar con su vestimenta sagrada aquel tipo de música. Aunque tuvo críticas negativas de parte de sus hermanos sacerdotes, las provenientes de su feligresía fueron positivas en general. "Ahora las cosas en el arte musical han cambiado mucho, se evidencia en los artistas un mayor profesionalismo; la música vallenata se ha cualificado. El hecho de que un sacerdote se presente en estos festivales, ya no es visto negativamente, sino como algo positivo". Agrega que los poemas de la Navidad Infantil y la advocación a la Virgen de Montserrat son de tinte religioso. Y cuando llegó a Ecuador hace trece años se impresionó porque no conocía a 
Virgen Morena patrona de la Iglesia Nuestra Señora de Montserrat del cual es párroco.

La Virgen de Montserrat, llamada popularmente «la Moreneta», por el color ébano del material con que fue construida, es una de las más conocidas y veneradas por los catalanes. Es una escultura de madera tallada, policromada y dorada que data seguramente de finales del s. XII o inicios del XIII. El color negro es su principal característica, de aquí procede el nombre de "moreneta” (Cánoves, Gemma, 2012, p. 69).

Aquellos días cercanos a su fiesta patronal les preguntó a los fieles si poseían alguna novena con sus gozos respectivos, y al verificar que no contaba con ellos, decidió investigar la historia desde su llegada a la Ciudadela 9 de Octubre en la ciudad de Guayaquil. Se inspiró y compuso lo que más que unos gozos resultó ser un poema de ocho estrofas en forma de sexteto de versos octosílabos. Los Gozos a la Virgen de Montserrat se encuentra publicado en Antología. La poesía religiosa en Guayaquil (Rubio, 2015 p. 48).

Del cielo a España bajaste para cumplir la misión y llena de bendición hasta Guayaquil llegaste para que con devoción todos podamos honrarte

Eres la de tez morena de tu raza protectora por eso el pueblo te implora mientras tu imagen venera y te amamos más ahora porque eres guayaquileña

(Gozos a la Virgen de Montserrat, 2005)

Con frecuencia suele decir: "Los dones de la poesía y de la música que el Señor me ha dado, los utilizo con fines religiosos para atraer los feligreses a la Iglesia; esto ocasiona que la gente esté dispuesta a escuchar el mensaje de Dios". Así, cuando compone una obra musical la comparte; y siempre termina hablando de Dios sin proponérselo. 


\section{Resultados}

\section{Métodos teóricos}

Para la elaboración de la línea teórica, se acudió a los métodos pertinentes: análisis-síntesis, inducción-deducción e histórico-lógico. Gracias al método de análisis-síntesis fue operable revisar con detalle los mecanismos concretos del contexto teológico que aparece en cada uno de los poemas religiosos, obteniendo como resultado conceptos significativos entre Dios y su pueblo. Con el método inductivo-deductivo se preparó las conclusiones de la investigación, explicando que verdaderamente los laicos están interesados en leer su poesía. No recurrieron previamente, puesto que no había difusión de la misma. El método histórico-lógico permitió examinar los grandes acontecimientos y exponentes de la época que participaron entorno a la vida del sacerdote mientras desarrollaba su obra.

\section{Método cuantitativo}

En la investigación se utilizó la encuesta para recopilar datos referentes al interés que tienen los laicos y miembros de la vida consagrada sobre la poesía religiosa. Por razones de tiempo, coste y complejidad en la recogida y análisis de información, se utilizó la selección de la muestra. La destreza de la muestra seleccionada fueron 68 personas la cual aportó las mismas características de la población. Este método estadístico-matemático permite obtener y elaborar datos de forma rápida y eficaz.

\section{Métodos cualitativos}

Debido a la naturaleza de la investigación, los datos de interés proporcionados por el sacerdote Teófilo eran: sus percepciones, pensamientos, experiencias y los procesos que se desarrollaron en el momento de escribir su poesía. Para la recolección de estos datos se empleó la técnica de campo de entrevista semiestructurada en donde cuenta las principales etapas de su vida y cómo esta las expresa en su poesía. Además el artículo utiliza técnicas bibliográficas y documentales apropiadas para la revisión de documentos y libros que pudieren argumentar al objeto de estudio que impliquen evidencias sustantivas para la demostración de los supuestos. 
Antes de empezar con la investigación de campo, se indagó toda la literatura respecto al tema de poesía religiosa para demostrar y evidenciar la necesidad de realizar este estudio. Aunque la exploración de los estudios previos fue una acción asociada a la investigación, en algunas fases del proceso se examinó en varias ocasiones la bibliografía para luego sumergirse en el ámbito. En varios casos, la anterior investigación sirvió para optimizar la recolección de datos y su posterior análisis; también para obtener un punto de divergencia de los resultados de la investigación, además de afirmar y profundizar las interpretaciones.

Como método cuantitativo se utilizó la encuesta realizada en el mes de agosto y septiembre del 2016. Como objetivo principal de este estudio fue descubrir la razón por la que no se lee poesía religiosa y a su vez indagar sobre algún posible interés sobre la poesía religiosa que ha escrito el padre Teófilo Gaivao Mier durante las diferentes etapas de su vida y cómo éstas son vehículos de la comunicación social entre Dios y su pueblo. A continuación estos fueron los resultados. Cuando se preguntó a las 68 personas cuál de las categorías prefieren leer, el 30\% de las personas encuestadas eligió los libros como sus favoritos, seguido de los artículo con un $32 \%$.

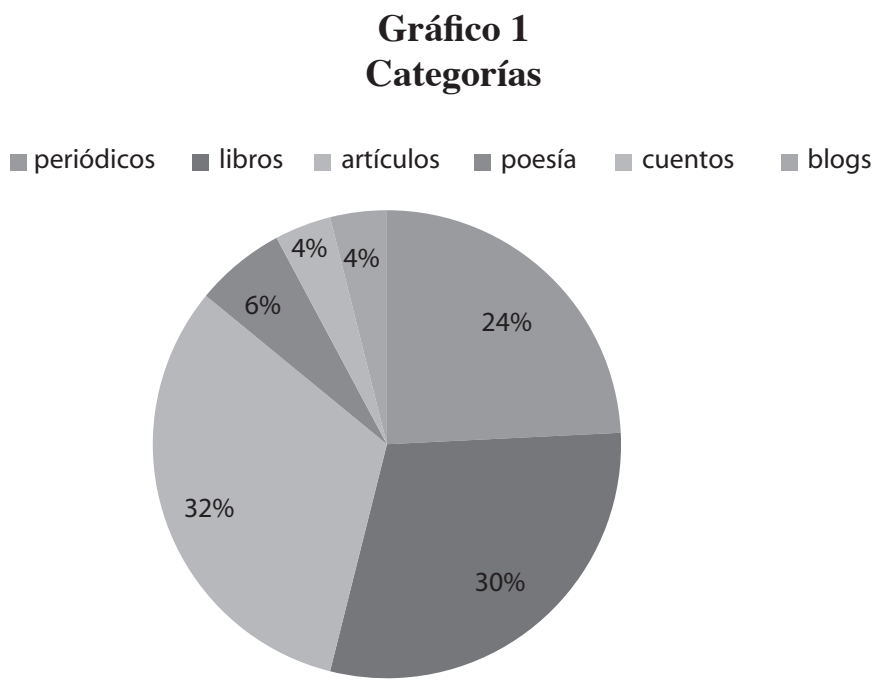

Fuente: Elaboración propia

El mejor día para dedicarse a leer, según los datos arrojados son tanto el viernes como el sábado con un $22 \%$ y $21 \%$ respectivamente. 


\section{Gráfico 2}

Mejor día para leer

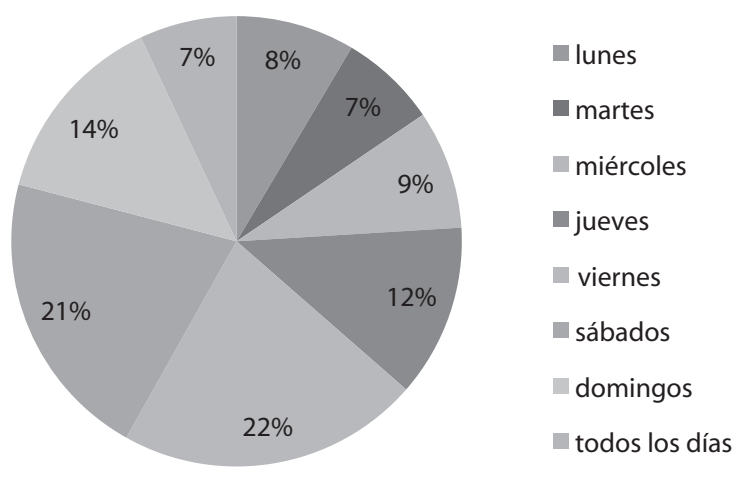

Fuente: Elaboración propia

En cuanto al horario de preferencia, la noche es su mejor aliada para leer a partir de las 20 horas hasta las 24 horas.

\section{Gráfico 3 \\ Horario de preferencia}

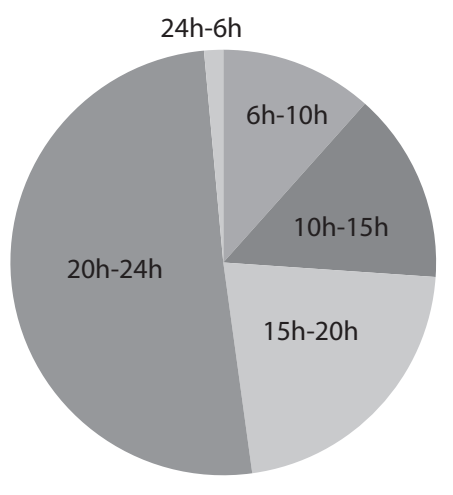

Fuente: Elaboración propia

Con respecto a la pregunta si por lo menos alguna vez ha leído poesía religiosa, la mayoría de los encuestados respondió de forma negativa con un $71 \%$ y afirmativa con un $29 \%$. 


\section{Gráfico 4 \\ Lectura de poesía religiosa}

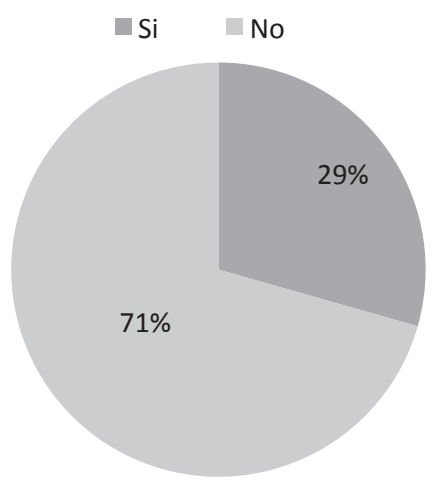

Fuente: Elaboración propia

Cuando se le preguntó la causa del por qué no la lee, contestaron: el 51\% porque no se difunde, el $31 \%$ por desconocimiento y el $18 \%$ porque simplemente no está interesado en la materia.

\section{Gráfico 5}

\section{Causas por no leer poesía religiosa}

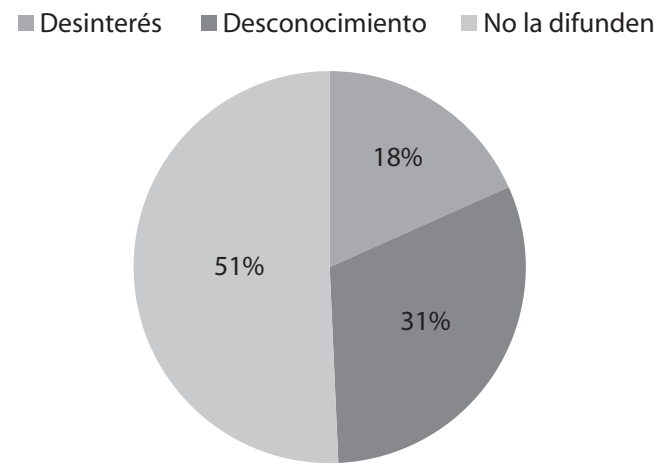

Fuente: Elaboración propia

Se propuso a los encuestados leer poesía religiosa y el 90\% respondió que sí le interesaría descubrirla. 


\section{Gráfico 6}

Propuesta de leer poesía religiosa

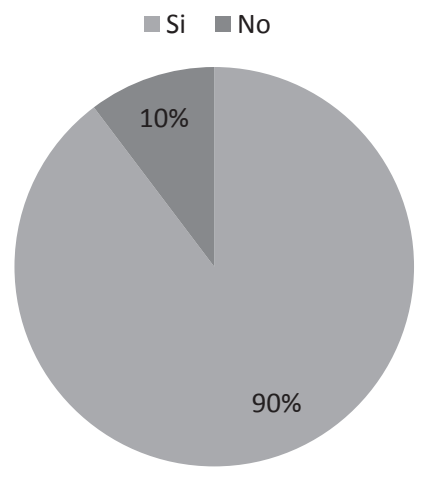

Fuente: Elaboración propia

Los laicos y miembros de vida consagrada respondieron tener gran interés por leer la poesía religiosa del padre Teófilo Gaivao con musicalización vallenata, de quien se habla en este artículo.

\section{Gráfico 7 \\ Poesía del Padre Teófilo Gaivao Mier}

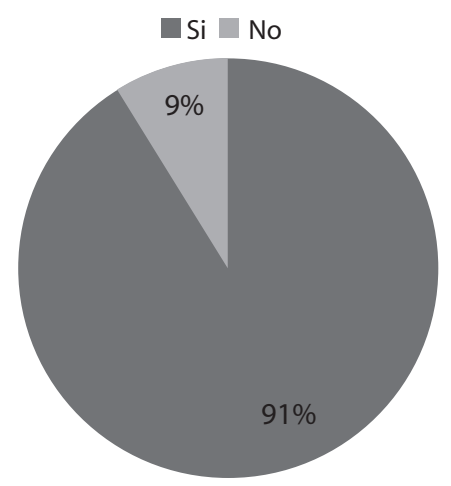

Fuente: Elaboración propia

En respuesta a la pregunta: ¿cree usted que los poemas religiosos del padre Teófilo Gaivao que se presentan son vehículo de comunicación social? 
Es decir, hay una comunicación entre Dios y su pueblo. E1 91\% afirma que sí existe una relación y el 9\% restante que no la hay.

\section{Gráfico 8 \\ Existe vehículo de comunicación entre Dios y su pueblo}

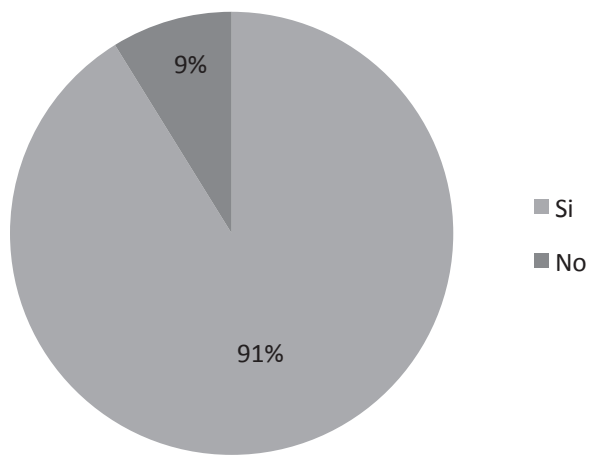

Fuente: Elaboración propia

\section{Conclusiones}

No se puede hablar simplemente de poesía religiosa sin vincularla con la comunicación social, cuando el poeta decide escribir poesía; él lo redacta, lo publica y alguien lo lee. Este proceso, que va de escritor a lector, tiene todas las características que definen un proceso comunicacional. Es decir, que interviene los elementos esenciales que lo componen: el poeta es el emisor, a su vez elabora un poema convirtiéndose en el mensaje, y finalmente éste va dirigido a un receptor. El fenómeno filosófico poético está determinado por las maneras de comunicación social que el poeta instituye, y el signo ideológico por excelencia, conformado a través de esa comunicación social organizada es la palabra. La palabra es adaptada por el poeta, unido al lenguaje interno, y restituida con los significados concedidos, significación establecida por su biografía, en nexo permanente con lo histórico biográfico. La palabra, como lenguaje interno, participa en la cognición misma del poeta. Así es la comunicación que hay entre Dios y su pueblo cuando Dios, al elegir Israel, simplemente lo elige y proclama: "Porque tú eres pueblo santo para el Señor tu Dios; el Señor tu Dios te ha escogido para ser pueblo suyo 
de entre todos los pueblos que están sobre la faz de la tierra” (Dt 7:6). La poesía religiosa del padre Teófilo Gaivao Mier como lenguaje poético es un acto completamente distinto del lenguaje ordinario y por lo tanto recalco la importancia de divulgarla.

Se ha cumplido con los objetivos planteados desde el inicio: Difundir la poesía religiosa del padre Teófilo Gaivao Mier como vehículo de la comunicación social mediante este artículo. Si bien es cierto cuando se preguntó a las 68 personas cuál de las categorías prefieren leer, el 30\% de las personas encuestadas eligió los libros como favoritos seguido de los artículo con un $32 \%$. El día exclusivo para dedicarse a leer los datos arrojaron que tanto el viernes como el sábado son de mayor agrado con un 22\% y $21 \%$ respectivamente. En cuanto al horario de preferencia, la noche es la mejor elección a partir de las 20 horas hasta las 24 horas. Con respecto a la pregunta si por lo menos alguna vez ha leído poesía religiosa, la mayoría de los encuestados respondieron negativo con un $71 \%$ y afirmativo $29 \%$. La causa del por qué no lee poesía religiosa, ellos contestaron: el 51\% no hay difusión, el 31\% por desconocimiento y el $18 \%$ porque simplemente no está interesado en la materia. Se propuso a los encuestados invitarlos a leer poesía religiosa y el $90 \%$ respondió que si le interesaría descubrirla. Los laicos y vida consagrada encuestados respondieron interés por leer la poesía religiosa del padre Teófilo Gaivao, de quien se habla en este artículo. En respuesta: ¿cree usted que los poemas religiosos del padre Teófilo Gaivao son vehículo de comunicación social? Es decir, hay una comunicación entre Dios y su pueblo. El 91\% afirma que sí existe una relación y el 9\% restante que no la hay.

De que hay interés y predisposición por leer poesía religiosa verdaderamente existe. Es oportuno compartir y difundir una poesía que todavía vive y además que está evolucionando. La poesía del padre Teófilo Gaivao Mier es simplemente una poesía atractiva con musicalización vallenata. Ahora sus feligreses la conocerán en el Festival de Talentos previsto para el 16 de octubre en el parque de la Iglesia Nuestra Señora de Montserrat. Poco a poco se irá reproduciendo de generación en generación.

\section{Recomendaciones}

La literatura no es simplemente un conjunto de contextos ya establecidos sino una comunicación social en el origen de una cultura en que se en- 
trelazan varios códigos no siempre estructurados como por ejemplo: éticos, ideológicos e institucionales. Por consiguiente de una teoría de la lengua literaria se salta a una teoría de la comunicación literaria meramente como práctica social. Lo literario no funciona como una condición de ser el lenguaje propiamente, sino más bien un modo de producirse el lenguaje, de actuar en el seno de una cultura en este caso una cultura poética.

Muy aparte de la gran relevancia que tiene este artículo para difundir la cultura poética recomiendo a los medios de comunicación y a los agentes culturales a promocionar las buenas noticias que la Iglesia Católica realiza, en este caso, lo que un sacerdote extranjero aquel representante de Dios en la tierra escriba poesía religiosa no es cosa de todos los días. Además invito a la feligresía indagar un poco más en la vida sacerdotal del párroco de su Iglesia. En fin de existir interés en leer poesía religiosa según los datos, verdaderamente la hay. Es cuestión de simplemente promoverla. Quitar esos tabúes de que lo religioso es aburrido, ya es pasado. La Poesía Religiosa del padre Teófilo Gaivao Mier como vehículo de la Comunicación Social es una poesía distinta y llamativa. Agradable a quien la lee y escucha.

\section{Bibliografía}

Casale Rolle, Carlos (2000). El tema trinitario en los 40 años de la revista Teología y Vida. Teología y vida, 41(3-4), 393-425.

Cánoves, Gemma (2006). Turismo religioso en Montserrat: montaña de fe, montaña de turismo. Cuadernos de turismo, 18, 63-76.

Casanova, Francisco (2007). Psicología evolutiva del niño (0 - 6 años). Bogotá: San Pablo.

Fausti, Silvano (2007). Una comunidad lee el Evangelio de Lucas. Bogotá: San Pablo. Grün, Anselm (2002). El orden sacerdotal: vida sacerdotal. España: San Pablo.

Juan Pablo II (1989). Discurso a los participantes en el VII Simposio de Obispos europeos sobre el tema "Las actitudes contemporáneas ante el nacimiento y la muerte: un desafío para la evangelización”. Carta Encíclica Evangelium Vitae.

Lopéz, Fernando (2014). Poesía y comunicación. Revista Anales, 372(1). Universidad Central del Ecuador.

Mattheeuws, Alain (2015). A new doctrine for the sacrament of marriage? Veritas, 32, $135-166$. 
Meschkat, Klaus (2010). El socialismo latinoamericano y su rescate del pasado Revista Izquierdas, 3(7).

Merchán Arias, Hugo (2015). Estudio exploratorio sobre las inferencias en los textos de poesía religiosa, en los jóvenes universitarios de la Carrera de Comunicación Social de la Universidad Politécnica Salesiana de Guayaquil en el año 2015. Universitas, XIII (23), 167-182.

Morillo-Velarde, Diego (2011). René Descartes: De omnibus dubitandum. España: Edaf.

Pieris, A. (2005). Vatican II: a "crisigenic" council with an unwritten agenda. East Asian Pastoral Review, 42, 7-24.

Rubio, Teodoro (2015). Antología. La poesía religiosa en Guayaquil. Quito: Abya-Yala.

Sánchez León, A. (2011). El amor como acceso a la persona: Un enfoque scheleriano del amor. Veritas, 25, 93-103.

Skidelsky, Robert (1995). The World After Communism. A Polemic for Our Times. Londres: Macmillan.

Stein, E. (2004). Escritos espirituales. España: Espiritualidad -El Carmen.

Taylor, Charles (2006). Imaginarios sociales modernos. Barcelona: Paidós. 


\section{Anexos}

Ilustración 1

Padre Teófilo Gaivao Mier

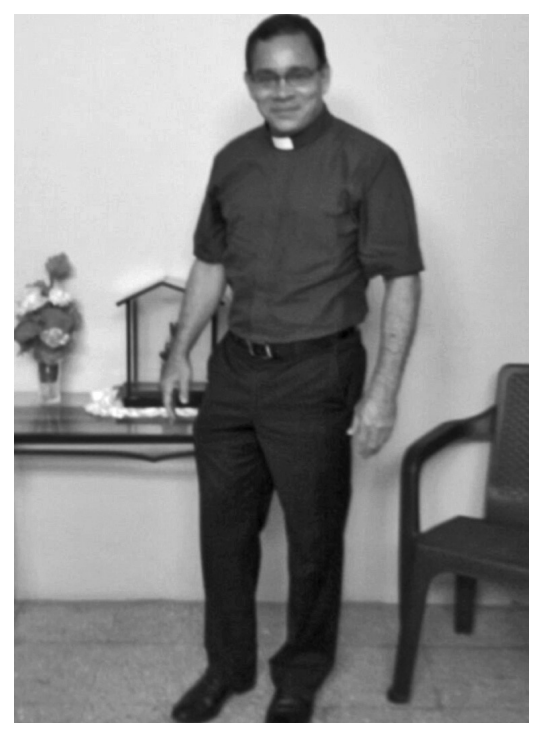

Ilustración 2

Padre Teófilo comparte sus poemas con Mons. Luis Gerardo

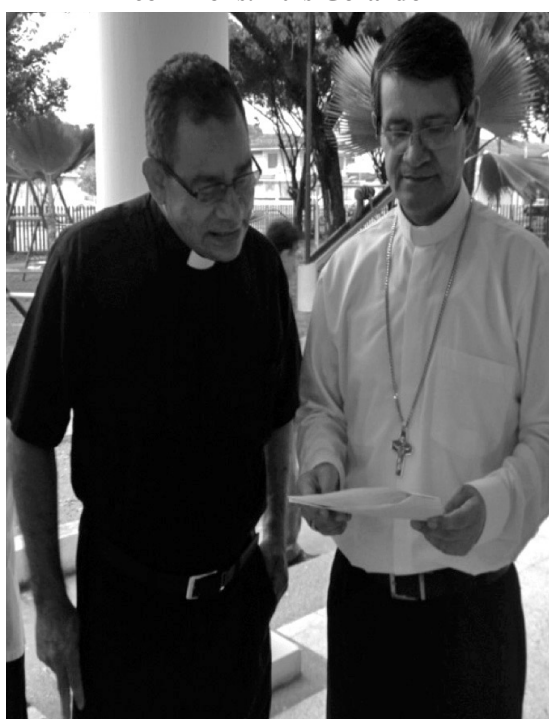

Ilustración 3

Virgen Nuestra Señora de Montserrat

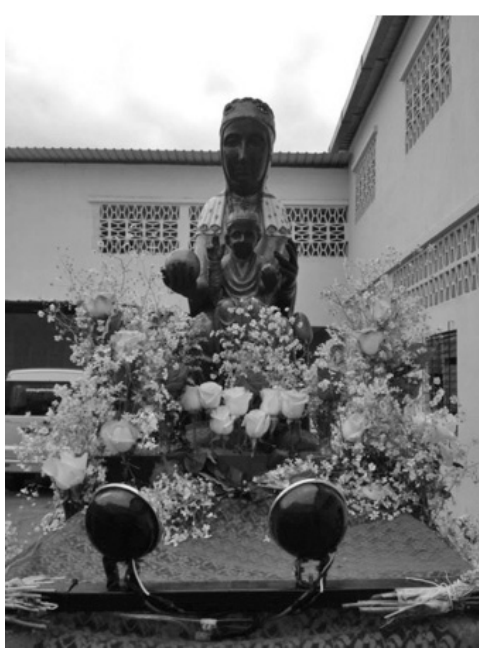




\section{Encuesta para determinar el interés sobre poesía religiosa a laicos y miembros de la vida consagrada}

\section{Nombre:}

1. Marque con una $x$ las categorías que usted prefiere leer:

$\begin{array}{lll}\text { ( ) periódicos } & \text { ( ) libros } & \text { () poesía } \\ \text { ( ) cuentos } & \text { ( ) artículos ( ) } & \text { Otra, especifique: }\end{array}$

2. ¿En qué día de la semana usted lee? Marque con una $\mathrm{x}$ una de las siguientes opciones:

() 1 . Lunes

( ) 2. Martes

( ) 3. Miércoles

() 4. Jueves

() 5 . Viernes

( ) 6. Sábados

() 7. Domingo

3. ¿En qué horario usted prefiere leer? Marque con una $x$ una de las siguientes opciones:

( ) 1 . De $6 \mathrm{am}$ a $10 \mathrm{am}$

( ) 2. De $10 \mathrm{am}$ a $15 \mathrm{pm}$

() 3. De $15 \mathrm{pm}$ a $20 \mathrm{pm}$

() 4. De $20 \mathrm{pm}$ a $24 \mathrm{pm}$

( ) 5. De $1 \mathrm{am}$ a $6 \mathrm{am}$

4. ¿Alguna vez ha leído poesía religiosa? Marque con una $\mathrm{x}$ una de las siguientes opciones:
() $1 . \mathrm{Si}$
( ) 2 . No

5. ¿Cuál cree que sea la razón? Marque con una $x$ una de las siguientes opciones:
( ) 1. Desinterés
( ) 2. Desconocimiento
( ) 3. No la difunden

6. ¿Le gustaría alguna vez leer poesía religiosa?
( ) $1 . \mathrm{Si}$
( ) 2. No

7. Si su respuesta fue afirmativa, responda: ¿Le gustaría leer la poesía religiosa del padre Teófilo Gaivao Mier?
() $1 . \mathrm{Si}$
( ) 2. No

8. ¿Si cree que la poesía religiosa del padre Teófilo Gaivao Mier es un vehículo de la comunicación social? ¿Existe comunicación entre Dios y el Pueblo?
( ) $1 . \mathrm{Si}$
( ) 2. No 